\title{
The profile of cardiovascular risk factors in heart failure obese patients hospitalised in a rehabilitation romanian hospital
}

Alexandra Dădârlat ${ }^{1}$, Adela Viviana Sitar-Tăut ${ }^{1}$, Dumitru Zdrenghea ${ }^{1,2,}$ Dana Pop ${ }^{1,2,}$ Anca Buzoianu ${ }^{1}$

1“'Iuliu Haţieganu" University of Medicine and Pharmacy, Cluj-Napoca

${ }^{2}$ Clinical Rehabilitation Hospital, Cardiology Department

Coresponding author: Dana Pop

E-mail address: pop67dana@gmail.com

Peer-reviewed by: Manoj Kumar, Department of Zoology, Ranchi University, Ranchi - 834008, Jharkhand (India)

Mariana Rotariu, “Grigore T. Popa” University of Medicine and Pharmacy, Iași

\section{Abstract \\ Introduction.}

Despite all advanced evidence-based therapeutic opportunities, heart failure remains a major public health burden, with a dramatically increasing in prevalence. Moreover, the diagnosis of chronic heart failure in obese patients brings unique challenges. So, the aim of this study was to identify the cardiovascular risk factors profile in heart failure obese patients, admitted in rehabilitation programs.

Material and methods.

This study enrolled 80 obese (body mass index $\geq 30 \mathrm{~kg} / \mathrm{m} 2$ ) patients, $56.2 \%$ men with average age ranged of $69.75 \pm 9.12$ years who were hospitalized for decompensated heart failure in the Rehabilitation Hospital, Cardiology-Department, Cluj-Napoca, Romania. Baseline characteristics, clinical presentation, NT-proBNP values, echocardiographic parameters and in-hospital therapies were evaluated. The lot was divided into three groups: obese heart failure patients with reduced $(<40 \%)$, preserved $(\geq 50 \%)$, and midrange (40-49\%) ejection fraction. Heart failure was defined according to 2016 ESC criteria. NT-pro-BNP values higher than 125 $\mathrm{pg} / \mathrm{ml}$ were considered to be associated with heart failure development. Statistics were performed using SPSS 16.0 for Windows.

\section{Results.}

The mean age of the analyzed study population was $69.75 \pm 9.12$ years and $56.2 \%$ were men. The most frequent associated risk factor was smoking (45\%), followed by diabetes mellitus (40\%) and hypertension (25\%). The mean ejection fraction value was $43.58 \pm 10.85 \%$ and the median value was $45 \%$. The mean NT-pro-BNP registered levels were $2887.03 \pm 3157 \mathrm{pg} / \mathrm{ml}$. An inverse relationship was found between NT-pro-BNP levels and plasma lipid fractions, total-cholesterol-r=-0.194, LDL-cholesterol-r=0.0971, triglycerides-r=-0.155, HDL-cholesterol-r=-0.07. Also, NT-proBNP negatively correlated with left ventricular ejection fraction-r=-0.307, $\mathrm{p}=0.0086$.

In conclusion, obese heart failure patients presented particular characteristics, the most frequent observed cardiovascular risk factors were smoking, diabetes mellitus and arterial hypertension. Identifying the major comorbidities in this subgroup of patients is of major importance, especially for improving heart failure's prognosis and survival.

Key words: heart failure, obesity, cardiovascular risk factors, NT-pro-BNP

\section{INTRODUCTION}

Heart failure represents a tremendous public health burden and a global pandemic worldwide and, moreover is increasing in prevalence [1]. Also, heart failure patients require an increased number of hospital admissions with a high number of hospitalization days. Although, in the recent years various treatments and initiatives to improve care delivery were developed, heart failure's evolution remains associated with an important morbidity and mortality [1].

Moreover, the presence of obesity in heart failure patients is frequently observed, bringing additional challenges in terms of heart failure diagnosis, treatment and prognosis. This is due to the fact that usually obese patients are presenting dyspnoea, oedema, a decreased exercise capacity, but also low acoustic echocardiographic images which limits the diagnostic accuracy [1].

Obesity is an independently acknowledged cardiovascular risk factor, also having strong links to the development of heart failure. Moreover, obesity and heart failure are two conditions frequently associated, so a comprehensive approach is needed for these patients taking into account certain particular features of their diagnosis, prognosis and treatment. One of the particularities described in this subpopulation is the existence of an "obesity paradox"- a clinical phenomenon in which obese patients with heart failure have a better prognosis than normal weight or underweight patients [2]. The prognosis of these patients is improved by a proper advanced treatment, but undoubtedly cardiovascular rehabilitation programs have a major role too [3]. They should include, besides physical training 
programs, the implementation of lifestyle change measures, which are of extreme importance in order to correct other cardiovascular risk factors associated with obesity [4].

The aim of the current study is to identify the cardiovascular risk factors profile in heart failure obese patients, hospitalized in the Rehabilitation Hospital, Cardiology-Department, who will be included in cardiovascular rehabilitation programs.

\section{MATERIALS AND METHODS}

The study included 80 obese patients with an averaged age of $69.75 \pm 9.12$ years, $56.2 \%$ of them being represented by men, who were hospitalized with a primary diagnosis of decompensated heart failure in the Rehabilitation Hospital, CardiologyDepartment, Cluj-Napoca, Romania. Inclusion criteria were a body mass index (BMI) $\geq 30 \mathrm{~kg} / \mathrm{m}^{2}$, diagnosis of heart failure (HF), in accordance with the 2016 ESC criteria. Exclusion criteria were age under 18 years, the presence of other comorbidities susceptible to significant systolic dysfunction, chronic kidney disease with a glomerular filtration rate $<30 \mathrm{ml} / \mathrm{min} / 1.73 \mathrm{~m}^{2}$ (KDOQI stage 4 and 5) and recent acute coronary syndrome. Baseline characteristics, clinical presentation, the aetiologies of heart failure, the functional NYHA class, NTproBNP values, electrocardiographic findings, echocardiographic parameters and in-hospital therapies were evaluated. NT-pro-BNP values higher than $125 \mathrm{pg} / \mathrm{ml}$ were considered to be associated with heart failure development. NT-pro-BNP levels were determined using the ELISA method. Hyperuricemia was defined as $\geq 7.0 \mathrm{mg} / \mathrm{dL}$ in males and $\geq 5.8 \mathrm{mg} / \mathrm{dL}$ in females. Statistics were performed using SPSS 16.0 for Windows. Analysis of the differences between qualitative variables was performed using the $\chi 2$ test. The Kolmogorov-Smirnov test was used to assess the normal distribution of continuous numerical variables. Values of $\mathrm{P}<0.05$ were considered statistically significant.

\section{RESULTS}

The baseline demographic and clinical characteristics of the patients are summarized in table 1 . The aetiology of heart failure was ischemic in $46.25 \%$ of cases and non-ischemic (toxic, abnormal loading conditions, such as hypertension, valve pathologies, various tachy- or bradyarrhythmias and genetic abnormalities) in $53.57 \%$ of patients. The most frequent associated risk factor was smoking (45\%), followed by diabetes mellitus (40\%). The plasma mean levels of all lipid fractions were between normal ranges: total-cholesterol (CST) -167.82 \pm $48.85 \mathrm{mg} / \mathrm{dl}$, LDL-CST $-102.40 \pm 39.5 \mathrm{mg} / \mathrm{dl}$, triglycerides (TG) $-145.68 \pm 81.91 \mathrm{mg} / \mathrm{dl}$, HDL-CST $38.64 \pm 11.42 \mathrm{mg} / \mathrm{dl}$, as shown in table 1 . The mean value of serum uric acid concentrations were high $8.07 \pm 2.35 \mathrm{mg} / \mathrm{dl}$.

Table I. Baseline characteristics of the study population

\begin{tabular}{ll}
\hline \multicolumn{2}{l}{ Baseline characteristics of total study population } \\
\hline $\begin{array}{l}\text { Age, median years } \pm \text { standard } \\
\text { deviation }\end{array}$ & $69.75 \pm 9.12$ \\
\hline Female sex - No (\%) & $35(43.7 \%)$ \\
\hline NYHA functional class & $\mathrm{II}-26(32.5)$ \\
\hline & $\mathrm{III}-43(53.7)$ \\
\hline Smoking status - No (\%) & $\mathrm{IV}-11(13.8)$ \\
\hline Cholesterol - mg/dl (mean \pm SD) & $36(45)$ \\
\hline HDL- CST mg/dl (mean \pm SD) & $167.82 \pm 48.85$ \\
\hline LDL- CST mg/dl (mean \pm SD) & $38.64 \pm 11.42$ \\
\hline $\begin{array}{l}\text { TG- mg/dl } \\
\text { (mean } \pm \text { SD) }\end{array}$ & $102.40 \pm 39.5$ \\
\hline $\begin{array}{l}\text { Glycaemia - mg/dl } \\
\text { (mean } \pm \text { SD) }\end{array}$ & $145.68 \pm 81.91$ \\
\hline Uric acid - mg/dl (mean \pm SD) & \\
\hline Diabetes - No (\%) & $116.25 \pm 36.33$ \\
\hline HTN - No (\%) & \\
\hline $\begin{array}{l}\text { NT-pro-BNP- pg/dl } \\
\text { (mean } \pm \text { SD) }\end{array}$ & $8.07 \pm 2.35$ \\
\hline Ejection fraction (mean \pm SD) & $32(40)$ \\
\hline
\end{tabular}

The mean ejection fraction value was $43.58 \pm 10.85 \%$. The mean NT-pro-BNP value was elevated - 2887.03 $\pm 3157 \mathrm{pg} / \mathrm{ml}$. NT-proBNP values correlated indirect with total-cholesterol - $\mathrm{r}==-0.194$ - figure 1 , LDLcholesterol-r=-0.0971, triglycerides- $r=-0.155$, HDLcholesterol-r=-0.07.

In male patients an indirect, significantly statistical correlation was found between NT-pro-BNP levels and total-cholesterol $(\mathrm{r}=-0.319, \mathrm{p}=0.036)$ - figure 2 . Also, NT-pro-BNP indirect correlated with left ventricular ejection fraction (LVEF) - $r=-0.307$, $\mathrm{p}=0.0086$ - figure 3 . This relationship was statistical significant in male patients $(\mathrm{r}=-0.423, \mathrm{P}=0.0067)$ in comparison with women where this association was not found $(\mathrm{r}=-0.156, \mathrm{p}>0.05)$. 


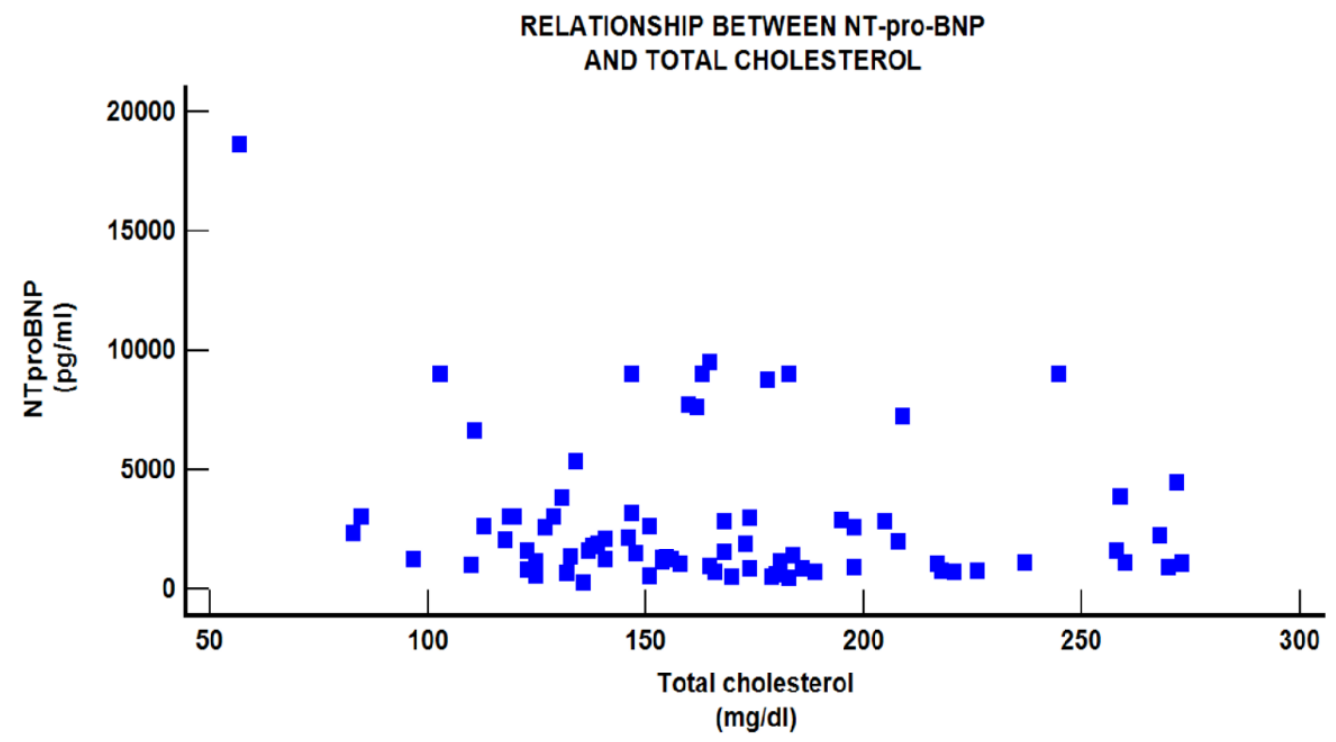

Fig. 1. Relationship between NT-pro-BNP and total cholesterol

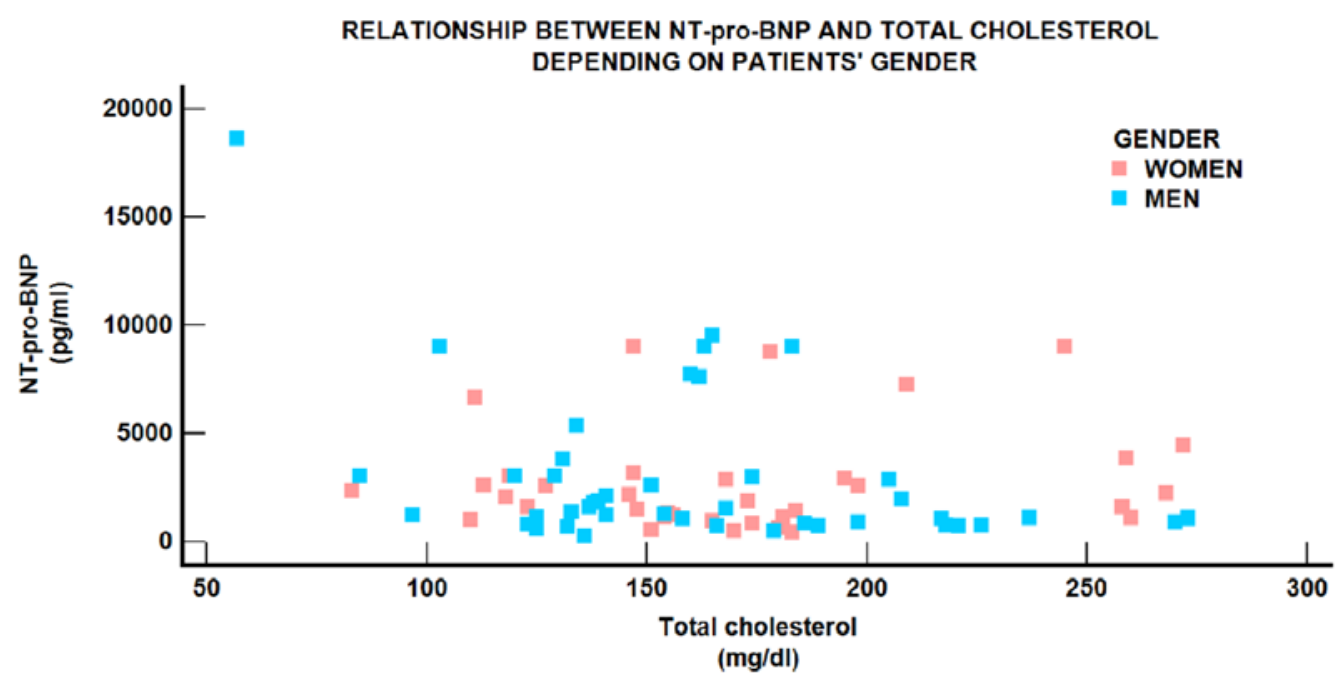

Figure 2. Graphic representation of the inverse relationship between NT-proBNP values and total cholesterol in men, respectively women

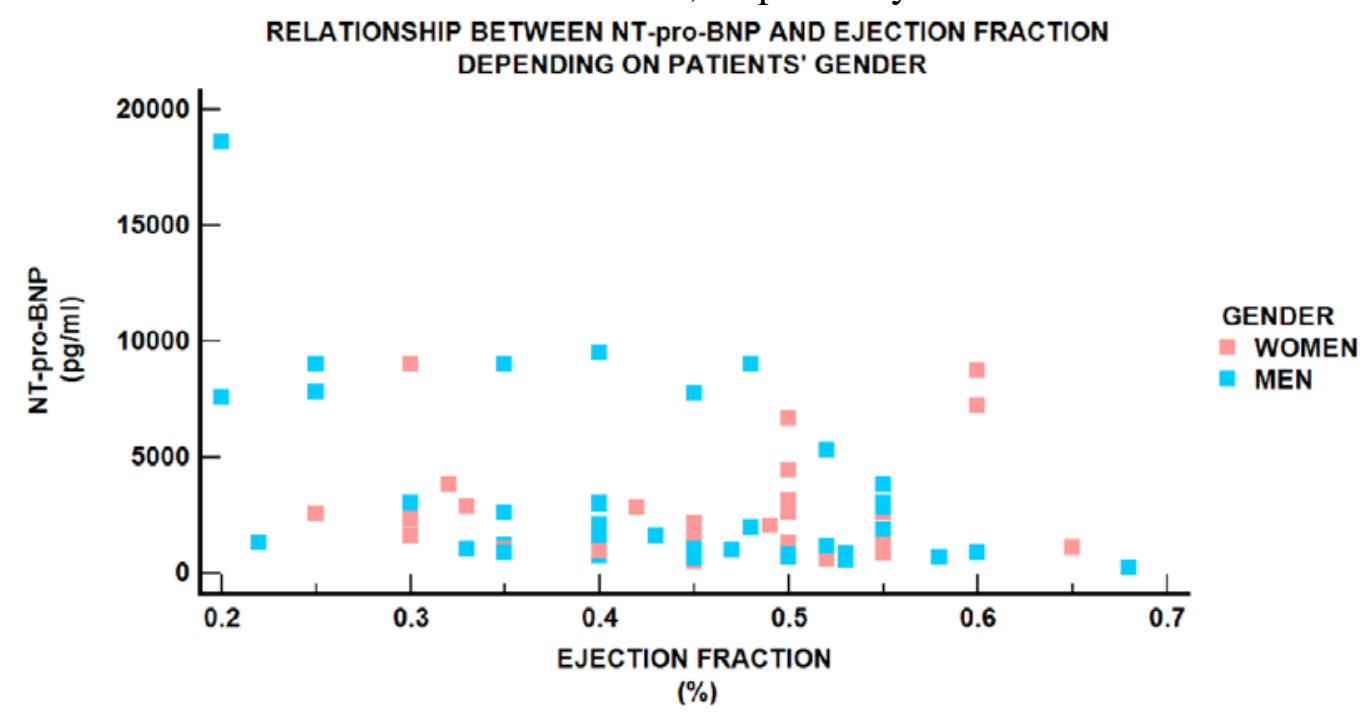

Figure 3. Sex differences regarding the relationship between NT-proBNP and left ventricular ejection fraction 


\section{DISCUSSION}

The link between obesity and cardiovascular pathology may be explained, on one hand, by the presence of other traditional cardiovascular risk factors such as arterial hypertension, dyslipidemia, type II diabetes, metabolic syndrome or sleep apnea syndrome in obese individuals [5]. The Framingham study showed an increased risk of developing heart failure of $5 \%$ for males and $7 \%$ for females for each BMI increase by one $\mathrm{kg} / \mathrm{m}^{2}$ [6]. In comparison with lean subjects, the risk of heart failure doubles in those with obesity, with a relative risk of 2.12 for women and 1.90 for males [7]. Moreover, obese patients present distinct features in terms of pathophysiology, etiology, diagnosis and treatment of heart failure, compared with their normal weight counterparts. So, they seem to have a predisposition for the phenotype with preserved ejection fraction, a more frequent ischemic etiology, earlier symptoms of HF, lower levels of natriuretic peptides, particular treatment challenges, but also more false-positive diagnoses of HF [8].

Therefore, the treatment of heart failure in this population should not only focus on pharmacological approach, but also on lifestyle changes and including these patients in physical training programs [9]. In Romania, after hospital discharge, heart failure patients are addressed for cardiovascular rehabilitation programs in specialized centers, such as Covasna Cardiovascular Disease Hospital. Physical exercise is recommended by the current guidelines in order to improve NYHA functional class and diastolic dysfunction [1]. To note that, obese patients often present a marked decreased exercise tolerance, with frequently abnormal blood pressure response and chronotropic stress incompetence. In the current study, $25 \%$ of patients were hypertensive. In Romania, the overall prevalence of hypertension continues to climb [10]. Recent studies show that high systolic and diastolic blood pressure in patients with heart failure increases the incidence of major adverse cardiac events, including cardiovascular mortality $[11,12]$.

Another commonly comorbidity found in heart failure patients is diabetes mellitus, the with a prevalence ranging between $30-40 \%$ [13]. Also, in our study the prevalence of diabetes was high (40\%). The presence of DM in heart failure patients rises the number of hospitalisations and the risk of mortality, compared to those without diabetes [14].
The most frequent associated cardiovascular risk factor in our study was smoking $-45 \%$ of the study's population was smoking. The smoking status is an important factor for heart failure's prognosis, smoking cessation being one of the main lifestyle changes recommendations in heart failure and not only $[1,9]$.

In the current paper, LDL-cholesterol and triglycerides levels were between normal ranges or even lower. There is strong evidence showing that lower levels of cholesterol in decompensated heart failure patients are independently associated with a worse prognosis [15]. Windler and al. showed that heart failure patients with lower total- cholestreol levels $(163.6 \mathrm{mg} / \mathrm{dl})$ have a higher mortality rate compared to those with higher total- cholesterol values (218 mg/dl) [16]. There are several pathways leading to altered cholesterol metabolism in heart failure patients, such as congestive hepatopathy, excessive proinflammatory cytokine synthesis or increased endotoxine activity [17-19].

Obesity is an independently acknowledged cardiovascular risk factor, but the presence of this condition in heart failure patients has been shown to be of better prognosis- the "obesity paradox" hypothesis. Thus, although weight loss is often recommended to improve the symptoms and to reduce cardiovascular risk factors, it is not associated with improved prognosis in heart failure [2]. Moreover, weight loss in patients with heart failure is associated with poor prognosis, increasing the risk of mortality and morbidity [2]. The ESC heart failure guideline highlights that weight loss may be considered only in patients with severe obesity (BMI between $35-45 \mathrm{~kg} / \mathrm{m}^{2}$ ), in order to manage symptoms and increase exercise capacity [1].

The mean NT-pro-BNP value was greatly elevated in our study. Generally, NT-pro-BNP serum levels are influenced by several factors, such as age, gender, arterial hypertension, renal function, body mass index, and thyroid function. Recent studies show decreased natriuretic peptide values in obese patients with heart failure $[1,20]$. An indirect correlation is described between plasma levels of natriuretic peptide biomarkers and BMI [21]. The pathophysiological mechanism of this relationship is not fully understood. A possible explanation could be that the C-type natriuretic peptide receptors (NPR-C) are well represented in the adipose tissue, lipolysis being partially accomplished at this level, leading to 
a lower serum concentration of natriuretic peptides in obese patients. But, on the other hand, NT-pro-BNP and NT-pro-ANP are different molecules than natriuretic peptides, so the above mentioned mechanism cannot explain their lower levels in obese heart failure patients. Reduced cardiac synthesis or secretion of natriuretic peptides may at least, partially explain this phenomenon [21,22]. In the current study, NT-pro-BNP values were inverse correlated with total-cholesterol, LDL-cholesterol, triglycerides values and ejection fraction, which was interpreted as a marker of poor prognosis.

Obese heart failure patients develop most frequently heart failure with preserved or mildly reduced left ventricular ejection fraction. In our study the median ejection fraction was of $45 \%$. There is evidence that heart failure with preserved ejection fraction is associated with an accelerated production and also an abnormal degradation of collagen [23]. ESC current guideline for the diagnosis and treatment of acute and chronic heart failure highlights that one out of six patients experiencing exertion symptoms of heart failure, who fits in the heart failure with preserved ejection fraction class remains undiagnosed [1].

In conclusion, obese heart failure patients presented particular characteristics, the most frequent associated cardiovascular risk factors were smoking, diabetes mellitus and arterial hypertension. So, a comprehensive evaluation with identification and an appropriate approach of their comorbidities is of major importance for the improvement of heart failure's prognosis.

\section{Bibliography}

1. Ponikowski P1, Voors AA, Anker SD, Bueno H, Cleland JG, Coats AJ, et al. 2016 ESC Guidelines for the diagnosis and treatment of acute and chronic heart failure: The Task Force for the diagnosis and treatment of acute and chronic heart failure of the European Society of Cardiology (ESC) Developed with the special contribution of the Heart Failure Association (HFA) of the ESC. Eur Heart J . 2016: 37 (27): 2129-2200.

2. Wannamethee SG, Shaper AG, Whincup PH, Lennon L, Papacosta O, Sattar N. The obesity paradox in men with coronary heart disease and heart failure: the role of muscle mass and leptin. Int J Cardiol 2014; 171(1):49-55.
3. Taylor RS, Sagar VA, Davies EJ, Briscoe S, Coats AJ, Dalal H, Lough F, Rees K, Singh S. Exercise-based rehabilitation for heart failure. Cochrane Database Syst

Rev. 2014;(4):CD003331. doi: 10.1002/14651858.CD003331.pub4.

4. Kinsara AJ. Do We Need Cardiac Rehabilitation in Heart Failure. J Coll Physicians Surg Pak. 2018 ;28(1):61-62.

5. Artham SM, Lavie CJ, Patel HM, Ventura HO. Impact of obesity on the risk of heart failure and its prognosis. J Cardiometab Syndr. 2008;3(3):155-61.

6. Hubert HB, Feinleib M, McNamara PM, Castelli WP (1983) Obesity as an independent risk factor for cardiovascular disease: a 26-year follow-up of participants in the Framingham Heart Study. Circulation 67:968-977

7. Kenchaiah S, Evans JC, Levy D, Wilson PW, Benjamin EJ, Larson MG, Kannel WB, Vasan RS (2002) Obesity and the risk of heart failure. N Engl J Med 347:305-313

8. Jhund PS. Obesity and heart failure: when 'epidemics' collide. Eur Heart J. 2017: 21;38(24):1934-1936

9. Pop D, Caloian B, Cismaru G, Guşetu G Roşu R, Comşa H, Zdrenghea D T. Secondary prevention- an essential component of the comprehensive rehabilitation of patients with heart failure. Balneo Research Journal. 2017;8(4):217-219

10. Darabont R, Tautu OF, Pop D, Fruntelata A, Deaconu A, Onciul S, Salaru D, Micoara A, Dorobantu M. Visit-to-Visit Blood Pressure Variability and Arterial Stiffness Independently Predict Cardiovascular Risk Category in a General Population: Results from the SEPHAR II Study. Hellenic J Cardiol. 2015;56(3):208-16.

11. Vogel MW, Slusser JP, Hodge DO, Chen

$\mathrm{HH}$. The natural history of preclinical diastolic dysfunction: a population-based study. Circ Heart Fail. 2012; 5:144-151.

12. Lip GY, Skjøth F, Overvad K, Rasmussen LH, Larsen TB. Blood pressure and prognosis in patients with incident heart failure: the Diet, Cancer and Health (DCH) cohort study.. Clin Res Cardiol.2015;104(12):1088-96

13. Handelsman Y, Bloomgarden ZT, Grunberger G, Umpierrez G, Zimmerman RS, Bailey TS, Blonde L, Bray GA, Cohen AJ, 
Dagogo-Jack S, Davidson JA, Einhorn D, Ganda OP, Garber AJ, Garvey WT, Henry RR, Hirsch IB, Horton ES, Hurley DL, Jellinger PS, Jovanovič L, Lebovitz HE, LeRoith D, Levy P, McGill JB, Mechanick JI, Mestman JH, Moghissi ES, Orzeck EA, Pessah-Pollack R, Rosenblit PD, Vinik AI, Wyne K, Zangeneh F. American association of clinical endocrinologists and american college of endocrinology - clinical practice guidelines for developing a diabetes mellitus comprehensive care plan - 2015.Endocr Pract. 2015;21 Suppl 1:1-87

14. Dunbar SB, Butts B, Reilly CM, Gary RA, Higgins MK, Ferranti EP, Culler SD, Butler J. A pilot test of an integrated self-care intervention for persons with heart failure and concomitant diabetes. Nurs Outlook. 2014 ;62(2):97-111

15. Horwich TB, Hamilton MA, Mc Lellan WR, Fonarow GC. Low serum total cholesterol is associated with marked increase in mortality in advanced heart failure. J Card Fail. 2002; 8: 216224.

16. Windler E, Wers-Grabow U, Thiery J, Walli $A$, Seidel $D$, greten $H$. The prognostic value of hypocholesterolemia in hospitalized patients. Clin Invest 1994; 72: 939-943.

17. Rauchhaus M, Clark AL, Doehner W. et al. The relationship between cholesterol and survival in patients with chronic heart failure. J Am Coll Cardiol.2003;42:1933-1940.

18. Charalambous BM, Stephens RC, Feavers IM, Montgomery HE Role of bacterial endotoxin in chronic heart failure: the gut of the matter..Shock. 2007; 28(1):15-23.

19. Niebauer J, Volk HD, Kemp M, Dominguez M, Schumann RR, Rauchhaus M, Poole-Wilson PA, Coats AJ, Anker SD. Endotoxin and immune activation in chronic heart failure: a prospective cohort study. Lancet. 1999; 353(9167): 1838-42.

20. Chow SL, Maisel AS, Anand I, Bozkurt B, de Boer RA, Felker GM, et al. Role of Biomarkers for the Prevention, Assessment, and Management of Heart Failure: A Scientific Statement From the American Heart Association. Circulation. 2017; 135(22):e1054-e1091.

21. Gruden G, Landi A, Bruno G. Natriuretic peptides, heart, and adipose tissue: new findings and future developments for diabetes research. Diabetes Care. 2014;37(11):2899-908.
22. Madamanchi C, Alhosaini H, Sumida A, Runge MS. Obesity and natriuretic peptides, BNP and NT-proBNP: mechanisms and diagnostic implications for heart failure. Int J Cardiol. 2014;176(3):611-7.

23. Zdrenghea DT, Ilea M, Zdrenghea M, SitarTăut AV, Pop D. The Effect of Maximal and Submaximal Exercise Testing on NT-pro-BNP Levels in Patients with Systolic Heart Failure. Revista Română de Medicină de Laborator. 2014;22:25-33.

24. De Boer RA, Edelmann F, Cohen-Solal A, Mamas MA, Maisel A, Pieske B. Galectin-3 in heart failure with preserved ejection fraction. Eur J Heart Fail. 2013;15(10):1095-101. 